\title{
Mechanical, surface and environmental evaluation of stone mastic asphalt mixtures with advanced asphalt binders using waste materials
}

\author{
Sara Fernandes (D), Hugo M. R. D. Silva (D) and Joel R. M. Oliveira (D) \\ CTAC, Centre for Territory, Environment and Construction, University of Minho, 4800-058 Guimarães, \\ Portugal
}

(Received 1 April 2017; accepted 12 September 2017)

\begin{abstract}
The reuse of waste materials in asphalt mixtures has been recently investigated, in order to develop new sustainable solutions for the road-paving industry. Such materials should improve the mechanical performance and provide safe/comfortable pavement surface courses for road users, without compromising their environmental performance. Thus, the aim of this study is to evaluate the mechanical, surface and environmental properties of stone mastic asphalt (SMA) mixtures produced with forward-looking asphalt binders incorporating waste materials. These binders were designed to maximise the waste material content using motor oil, high-density polyethylene, styrene-butadiene-styrene and crumb rubber, while performing so well as a commercial modified bitumen. Finally, the overall performance of the SMA mixtures produced with the selected binders was evaluated. It was concluded that these mixtures improve the water sensitivity, fatigue cracking and permanent deformation performance. The requirements for macrotexture, skid resistance and presence of heavy metals in leachates of these mixtures were similarly fulfilled. Thus, this work shows that new asphalt mixtures with waste materials can be used in road-paving works to improve the performance without compromising human and environmental safety.
\end{abstract}

Keywords: modified bitumen; waste materials; stone mastic asphalt; mechanical performance; surface properties; leaching

\section{Introduction}

The asphalt mixtures with modified bitumens resulted from the need for reducing the main problems of the conventional asphalt mixtures, such as permanent deformation, fatigue cracking and thermal susceptibility, particularly under more demanding service conditions (Branco, Pereira, \& Picado, 2006; Fuentes-Audén et al., 2008; Yousefi Kebria, Moafimadani, \& \& Goli, 2015).

Even though the bitumen content in an asphalt mixture is significantly lower in comparison to the aggregate content, its characteristics are the most influential in asphalt mixtures' performance. Therefore, additives or modifiers are used to improve binder characteristics (Ahmedzade, 2013; Arslan, Gürü, Çubuk, \& Çubuk, 2011), being polymers the most used additives in asphalt mixtures (Dehouche, Kaci, \& Mokhtar, 2012). Styrene-butadiene-styrene (SBS) copolymer is one of the most appropriate and common polymer used for bitumen modification (Júnior, Battistelle, Bezerra, \& Castro, 2012; Yildirim, 2007), because it increases the rut resistance at high temperatures and the fatigue cracking resistance at low/intermediate temperatures. Moreover, it improves the tensile strength and elastic recovery properties of the resulting binder (Ahmedzade, 2013).

*Corresponding author. Email: hugo@civil.uminho.pt 
Some studies refer that the use of waste polymers for bitumen modification presents similar properties when compared with the virgin ones. Thus, the use of waste polymers could result in environmental and economic advantages combined with a good performance (Fuentes-Audén et al., 2008; González, Martínez-Boza, Gallegos, Pérez-Lepe, \& Páez, 2012). Some of the most commonly used waste polymers are waste high-density polyethylene (HDPE) and crumb rubber recycled from waste tires. The HDPE decreases cracking at low temperatures, thermal susceptibility and also improves the rut resistance (Attaelmanan, Feng, \& Ai, 2011; Nejad, Azarhoosh, $\&$ Hamedi, 2014). The crumb rubber improves the fatigue and reflexive cracking resistance and the rut resistance (Peralta et al., 2012).

Other wastes can be used as additives for bitumen modification, although with a different objective. For example, waste motor oil has the potential for being used as bitumen partial substitute or rejuvenator due to its effect in improving the asphalt mixtures performance at low temperatures. However, the content of such additive must be limited in order not to compromise the rut resistance at high temperatures (Jia, Huang, Bowers, \& Zhao, 2014) or the skid resistance of the mixtures if used in surface courses.

Using waste motor oil as a modifier or as partial substitute of the bitumen, and not just as rejuvenator, can be of great interest due to the consequent reduction in the consumption of an important, scarce and expensive oil derived resource. However, polymers may be needed as a second modifier to control potential permanent deformation problems when higher amounts of waste motor oil are used. For example, some studies have demonstrated that the simultaneous addition of crumb rubber (elastomer) and bio-oil as bitumen modifiers resulted in asphalt rubber binders and mixtures with improved performance (Peralta et al., 2012; Peralta, Silva, Williams, Rover, \& Machado, 2013; Peralta, Williams, Silva, \& Machado, 2013).

Nevertheless, it should be emphasised that the use of waste materials in asphalt mixtures should always be accompanied by a life-cycle analysis, in order to confirm if those are the most optimal solutions for the waste materials. In fact, the sustainability of those solutions is a very complex interplay of a lot of factors that should continue to be studied in future works to confirm all the pros and cons of such solutions.

As mentioned by Reinke et al. (2016), the re-refined motor oil could also have a negative impact on bitumen long-term ageing and lead to premature pavement surface cracking. Those properties are not addressed in this paper, as their evaluation is not required in the country where the research work was carried out. However, the evaluation of long-term ageing and low temperature cracking of these mixtures, as well as their recyclability should be evaluated in future works.

Despite the possible economic and environmental advantages of using such waste materials in asphalt mixtures, by the reduction of resources consumption and wastes disposal, it is also important to assure that the corresponding mixtures will not be detrimental for human health or the local ecosystems, namely by the run-off of these mixtures. Moreover, when used in surface courses, the characteristics of these mixtures must assure the safety and comfort of road users.

Therefore, the main goal of this study is to assess the mechanical, surface and environmental characteristics of stone mastic asphalt (SMA) mixtures incorporating binders modified with different waste materials. Their characteristics should be compared with those of SMA mixtures produced with a conventional and a commercially available polymer-modified bitumen (PMB), in order to confirm the enhanced properties of these new mixtures.

\section{Materials and methods}

\subsection{Materials}

Taking into account the objective of this work, a conventional bitumen with a penetration of $35 \times 0.1 \mathrm{~mm}$ and a softening point temperature of $54^{\circ} \mathrm{C}$ was modified with different waste materials. 
Table 1. Selected gradation of the SMA 14 mixtures.

\begin{tabular}{lccc}
\hline & \multicolumn{3}{c}{ Percent passing $(\%)$} \\
\cline { 2 - 4 } Sieve size $(\mathrm{mm})$ & Selected gradation & Envelope lower limit & Envelope upper limit \\
\hline 20.0 & 100.0 & 100.0 & 100.0 \\
14.0 & 92.9 & 90.0 & 100.0 \\
10.0 & 56.8 & Not required & Not required \\
6.3 & 28.3 & Not required & Not required \\
2.0 & 21.4 & 15.0 & 30.0 \\
0.063 & 7.0 & 5.0 & 12.0 \\
\hline
\end{tabular}

A waste motor oil without treatment, obtained from a waste managing company, was used to partially substitute bitumen in order to reduce its use in asphalt mixtures. This waste material was not treated in order to evaluate the worst-case scenario regarding the environmental impact of its use. The waste motor oil is mainly characterised by its dynamic viscosity, which presents a value lower than $0.1 \mathrm{~Pa} . \mathrm{s}$ (according to EN 13302 standard), tested in a range of temperatures between room temperature and $180^{\circ} \mathrm{C}$. Thus, when added to the conventional bitumen, it will reduce the viscosity/stiffness of the resulting blend in all temperature range. Additionally, its flash point temperature (EN 22592) was determined to assess whether or not its use with very high temperatures would be a potential problem, and the result obtained was around $200^{\circ} \mathrm{C}$. Nevertheless, during the bitumen modification process such temperature is never achieved (in this study, the maximum temperature used was $180^{\circ} \mathrm{C}$ ). After incorporation in the binder, the flash point temperatures of the several samples tested were always above $300^{\circ} \mathrm{C}$, which is clearly higher than the minimum temperature required for a PMB45-80 binder (according to EN 14023), which is $235^{\circ} \mathrm{C}$.

Different waste polymers, typically available in significant quantities, were also used for bitumen modification: (i) a crumb rubber (R) obtained from waste tires by ambient grinding, with dimensions between 0.18 and $0.60 \mathrm{~mm}$ and (ii) a ground HDPE waste plastic with a maximum dimension of $4 \mathrm{~mm}$. Besides these waste polymers, SBS was also used due to its well-known characteristics for bitumen modification in the paving industry, and it presents a maximum dimension of $4 \mathrm{~mm}$.

The new modified binders developed in this work will be obtained by combining the conventional bitumen with different amounts of waste motor oil and each one of the abovementioned polymers. The best combinations are then used to produce SMA mixtures for performance evaluation. Additionally, SMA mixtures produced with the conventional bitumen and acrylic fibres (6-12 mm length and nominal diameter of $14.4 \mu \mathrm{m})$, and also with a commercially available polymer-modified bitumen (PMB 45/80-60) are also used for comparison purposes.

Regarding the aggregate selection to obtain the desired gradation (as presented in Table 1) for an SMA 14 mixture (EN 13108-5), different fractions of material were used, namely a 0/4 fraction of crushed granite (21\%), a 6/14 fraction of crushed granite (74\%) and a limestone filler $(5 \%)$.

\subsection{Methods}

This study started with the production of several modified binders and their characterisation. It should be noted that during this phase, the objective was to maximise the use of waste materials, while assuring that the new modified binders showed characteristics of a PMB 45/80-60 bitumen (EN 14023) used as a reference. 


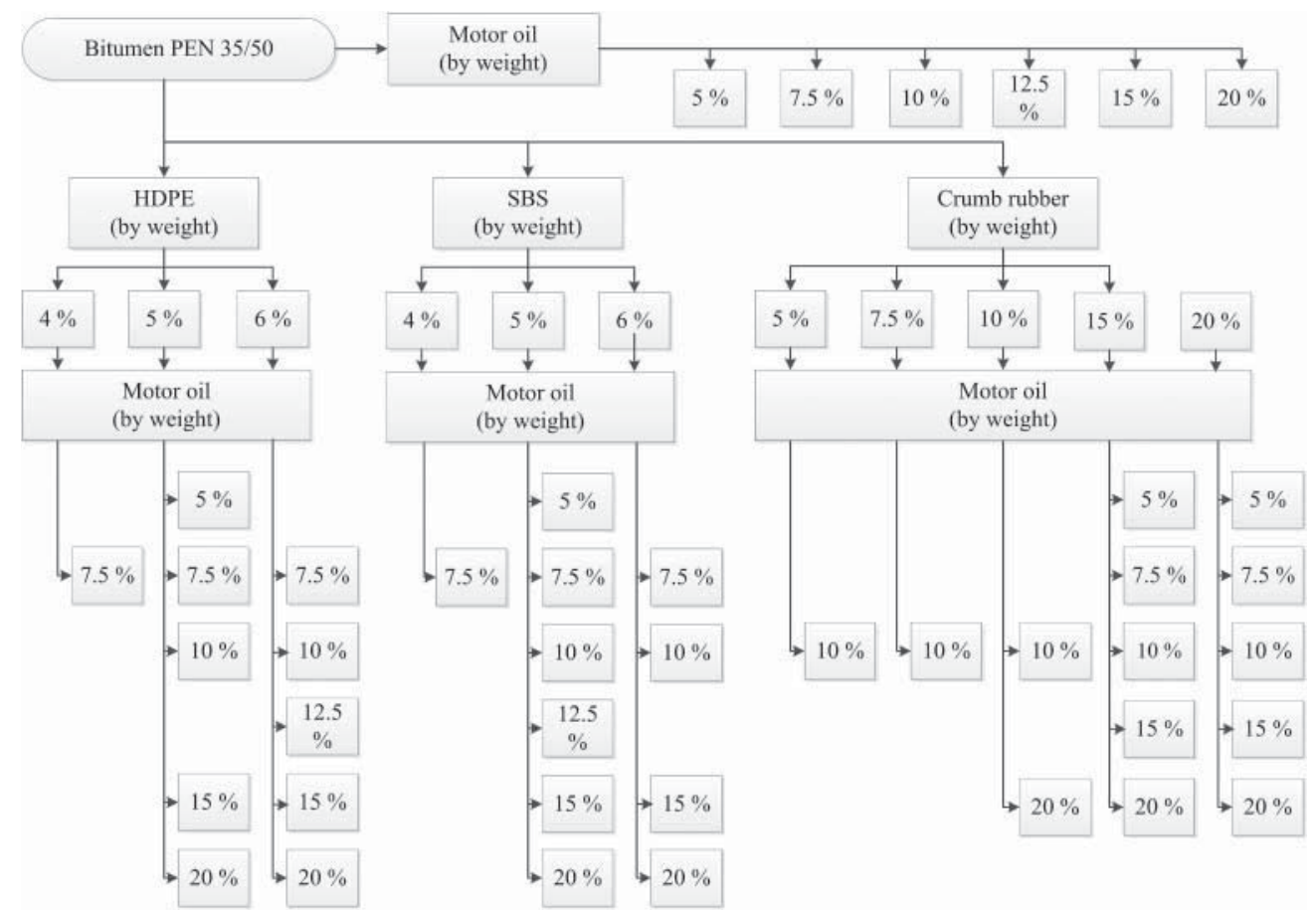

Figure 1. Type and amount of materials used for bitumen modification.

The SBS and HDPE polymer contents most used for bitumen modification vary between 3\% and 7\% (Attaelmanan et al., 2011; Dehouche et al., 2012). However, in the last decades, 5-6\% polymer amounts have become more common (Kalantar, Karim, \& Mahrez, 2012). However, in the case of crumb rubber, it is possible to add higher amounts (up to about 20\%) in the modification process (Kök \& Çolak, 2011; Lo Presti, 2013; Peralta, Williams, et al., 2013; Sarang, Lekha, Krishna, \& Ravi Shankar, 2016). Based on these references, the main range of polymer contents was defined, and different motor oil contents were evaluated. The combination and the contents of each material used to produce the modified binders can be observed in Figure 1.

The high amount of combinations used was defined in order to assess the most influential variables in each property of the obtained modified binders, for an adequate selection of the binders/modifiers to be used during the SMA mixture production, as shown in the outline of the experimental study (Figure 2).

The modified bitumens were produced in a high-shear mixer (IKA T 65 D ULTRA-TURRAX) at a speed of between 6000 and $7200 \mathrm{rpm}$, during $20 \mathrm{~min}$, at a temperature between $170^{\circ} \mathrm{C}$ and $180^{\circ} \mathrm{C}$ based on Fernandes, Costa, Silva, and Oliveira's (2015) study. Then, the basic characteristics of all binders were obtained by carrying out penetration (EN 1426) and softening point temperature (EN 1427) tests. The bitumens modified with waste materials meeting the PMB 45/80-60 specification and maximising the amount of waste materials were selected for rheological characterisation.

The rheological analysis of those binders was carried out using a dynamic shear rheometer (DSR) AR-G2 equipment from TA instruments. First, the high temperature continuous performance grade (PG) was determined according to EN 14770 standard, for a range of frequencies between 0.1 and $20 \mathrm{~Hz}$ at several test temperatures. Then, the different binders were also evaluated through the multiple stress creep recovery test (MSCRT), according to AASHTO TP 70-11 


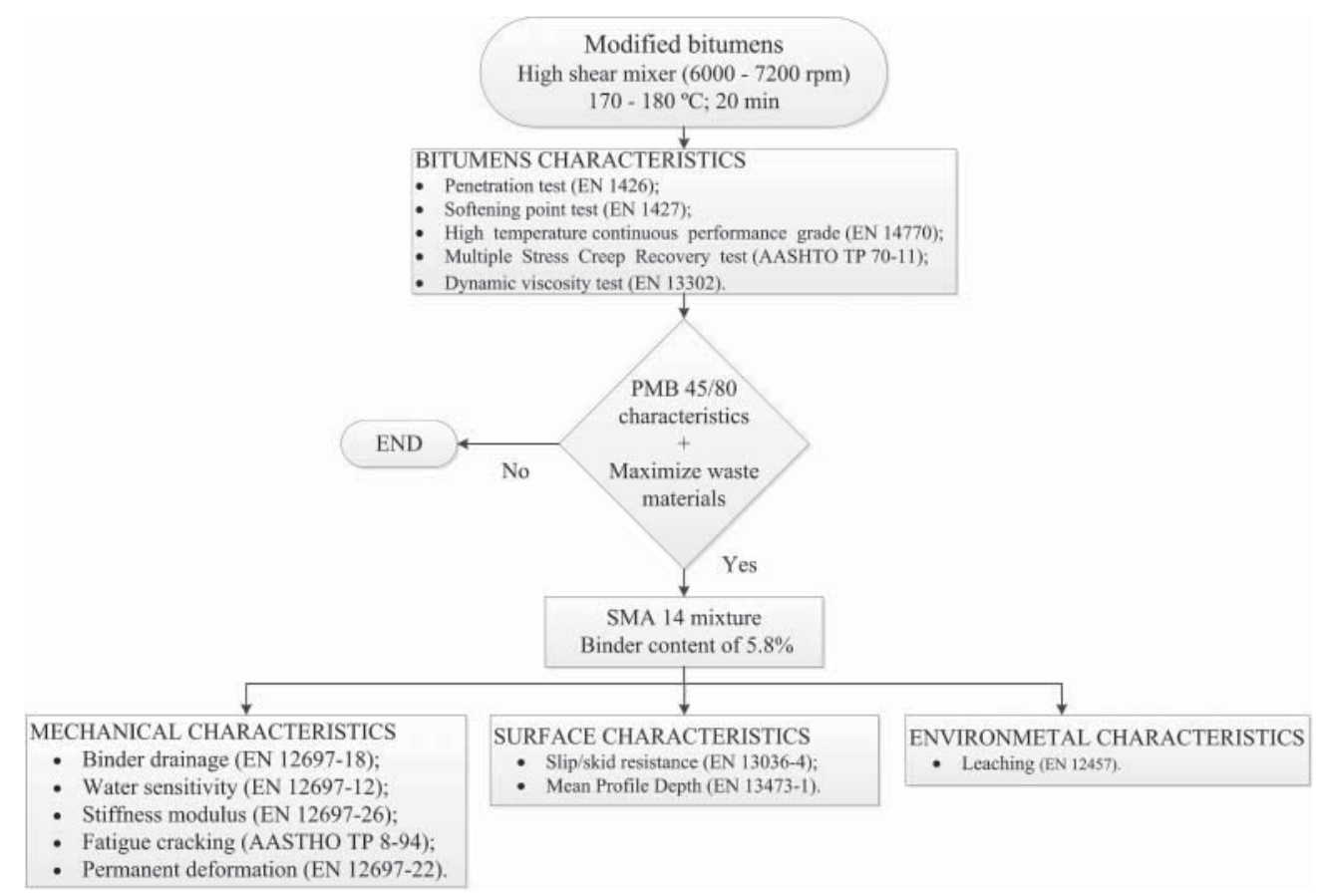

Figure 2. Outline of the experimental study.

standard, under two different stress levels $(0.1$ and $3.2 \mathrm{kPa})$ in order to get the asphalt binder non-elastic response. The samples were subjected to cycles of $1 \mathrm{~s}$ of stress application and $9 \mathrm{~s}$ of recovery (this cycle is performed 10 times for each stress level mentioned). Finally, the bitumens modified with waste materials showing the best performance in these rheological tests were selected for asphalt mixture production.

Then, five SMA 14 mixtures were produced with the selected bitumens (one for each type of polymer, one with a conventional bitumen and other with a commercial PMB) at a binder content of 5.8\%, obtained by the Marshall mix design method (EN 13108-5 and EN 12697-34). The mixing and compaction temperatures of each mixture were defined based on the corresponding bitumen dynamic viscosity test results according to EN 13302 standard, carried out using an Ametek Brookfield viscometer model DV-II + over a range of temperatures of $100^{\circ} \mathrm{C}-180^{\circ} \mathrm{C}$, with $10^{\circ} \mathrm{C}$ increments.

For the reference SMA 14 mixture with the conventional bitumen, $0.3 \%$ of fibres were added to reduce the bitumen drainage during mixture handling. This value has been suggested by the supplier and it is also the most commonly used for this type of application according to Gardete, Santos, and Capitão (2011). Fibres were not included in the other mixtures, in order to evaluate the actual performance of the polymer-modified binders in this kind of mixtures (since PMBs should not have drainage problems). Nevertheless, binder drainage tests were carried out for all mixtures, using the basket method (EN 12697-18), in order to confirm that the drainage values are within acceptable limits (Blazejowski, 2011).

All SMA mixtures were evaluated by a series of mechanical tests related with the performance of asphalt mixtures under different service conditions, namely:

- water sensitivity tests, in which the ratio between the indirect tensile (IDT) strength (assessed in a Matest S212N universal loading frame) of unconditioned and water conditioned specimens is evaluated according to EN 12697-12 standard; 
- stiffness modulus tests, in accordance with EN 12697-26 standard, carried out in a four-point bending beam configuration in a CS 7800 equipment from James Cox \& Sons;

- fatigue cracking resistance tests at $20^{\circ} \mathrm{C}$, according to AASTHO TP 8-94, carried out in a four-point bending beam configuration in a CS 7800 equipment from James Cox \& Sons and

- the permanent deformation resistance test at $60^{\circ} \mathrm{C}$, according to EN $12697-22$, carried out in a Wessex 867 Wheel Tracking Machine.

Then, since SMA mixtures are typically used in surface courses, their surface characteristics were also assessed, namely the slip/skid resistance (EN 13036-4) measured with the British Pendulum Tester and the macrotexture, expressed by the mean profile depth (MPD) value (EN 134731). The MPD was measured in the laboratory on rectangular pavement slabs, using a purpose developed profilometer with an electro-optical sensor, according to EN 13473-1 standard.

Finally, due to the use of waste materials in the SMA mixtures, it is important to evaluate their ecotoxicity, because the waste materials may result in leachates that can contaminate soils and watercourses, affecting the ecosystems and presenting potential risks to human health. The evaluation of the environmental impact of these new solutions was made by assessing the heavy metals presence in their eluate according to EN 12457 standard, using an atomic absorption spectroscopy instrument.

\section{Results and discussion}

\subsection{Properties of the modified binders}

The first part of this work comprised the development of new modified binders produced with waste motor oil and different polymers. These were mainly characterised through penetration and softening point tests, as previously mentioned. Taking into account the high number of samples tested, it was possible to compute contour graphs with the modified binder properties using the origin data analysis and graphing software, respectively for HDPE (Figure 3), SBS (Figure 4) and crumb rubber (Figure 5). These graphs show the evolution of binder properties as a result of the addition of different amounts of waste motor oil and polymer to the bitumen. The relevance of these graphs can be highlighted because they show which type of additive (waste motor oil or polymer) is more influent in the modified binder properties, as well as some transition zones

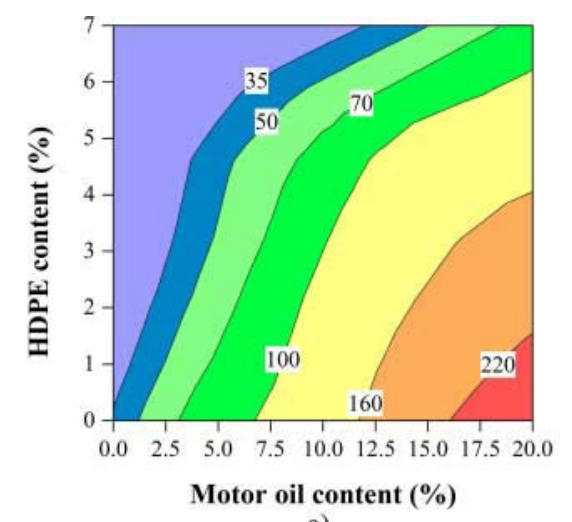

a)

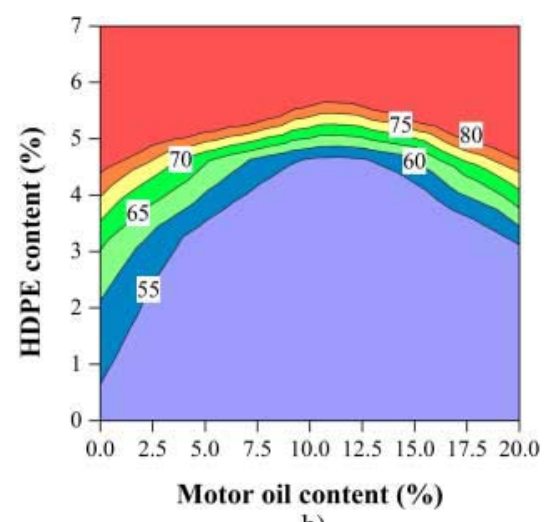

b)

Figure 3. Combined influence of used the motor oil and waste HDPE content on PMB properties: (a) penetration $(0.1 \mathrm{~mm})$ and (b) softening point temperature $\left({ }^{\circ} \mathrm{C}\right)$. 
for selection of optimum amounts of each modifier and also possible combinations that could be used for other purposes.

Therefore, Figure 3 shows that the content of waste motor oil has more influence in the penetration values (contour lines tend to be closer to the vertical direction) than in the softening point temperatures. The softening point temperature is more influenced by the amount of polymer used, in this case HDPE, than by the motor oil content (contour lines tend to be closer to the horizontal direction). Moreover, the penetration values increase for higher amounts of motor oil and decrease for higher amounts of HDPE (Figure 3(a)). On the other hand, the softening point values mainly increase when HDPE contents are increased. The curvature noticeable in Figure 3(b) indicates a transition phase for the softening point temperatures at a motor oil content around $12.5 \%$. This means that the interaction between the waste motor oil and the HDPE change its nature at this point, probably because this is the amount needed to facilitate the dispersion of HDPE in the modified binder. A transition phase is also visible in Figure 3(a) for HDPE contents around 5-6\%, confirming the typical values presented by Kalantar et al. (2012) for bitumen modification.
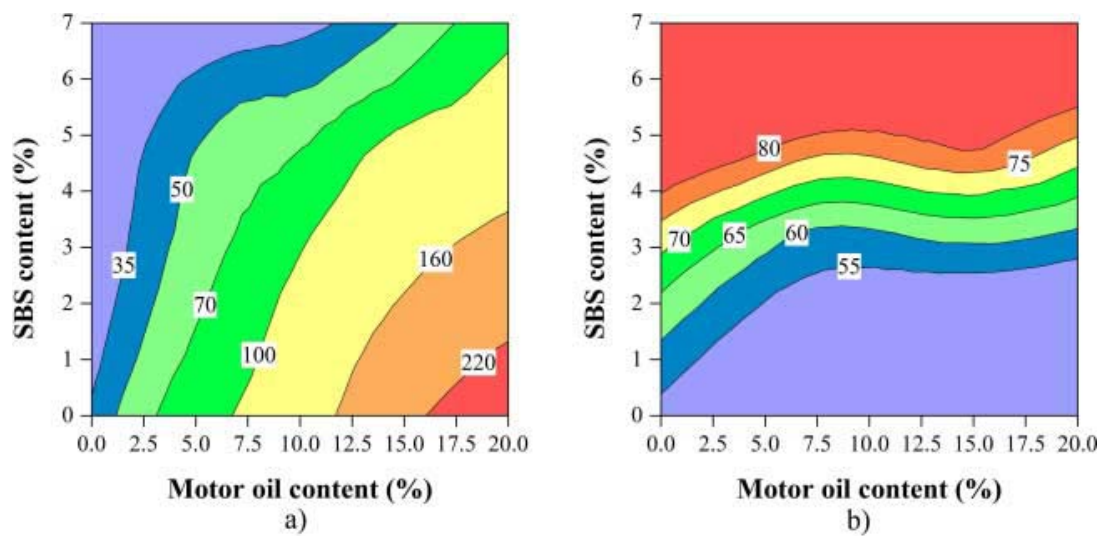

Figure 4. Combined influence of used the motor oil and SBS content on PMB properties: (a) penetration $(0.1 \mathrm{~mm})$ and (b) softening point temperature $\left({ }^{\circ} \mathrm{C}\right)$.

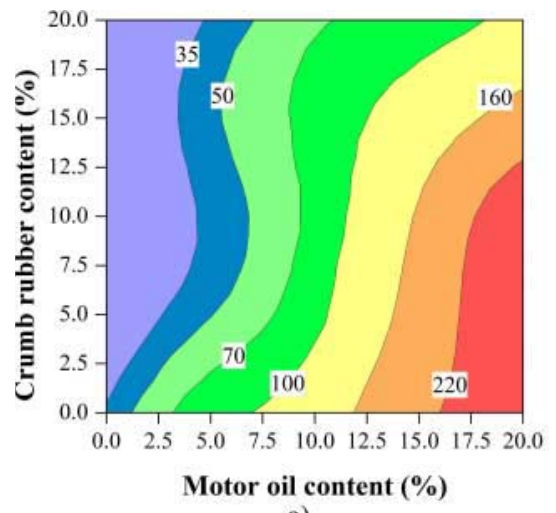

a)

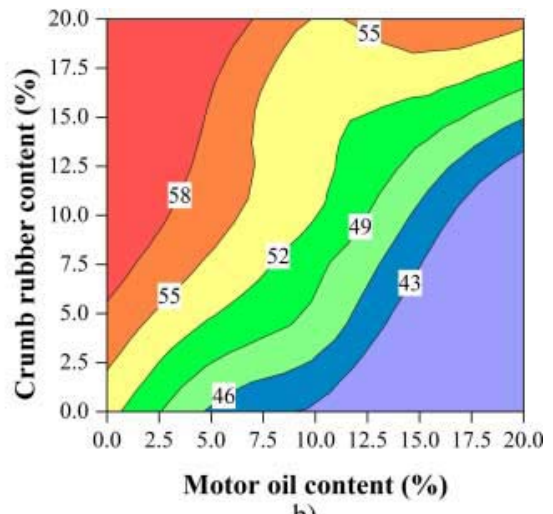

b)

Figure 5. Combined influence of used the motor oil and crumb rubber content on asphalt rubber properties: (a) penetration $(0.1 \mathrm{~mm})$ and $\mathrm{b}$ ) softening point temperature $\left({ }^{\circ} \mathrm{C}\right)$. 
Regarding the results obtained for the binders modified with motor oil and SBS, the shape of the contour lines for their penetration values (Figure 4(a)) is similar to that observed for the HDPE-modified bitumens. In other words, the penetration values are more closely influenced by the motor oil content than by the SBS content. On the other hand, the SBS content has a much higher influence on the softening point temperatures. A motor oil content of around $7.5 \%$ defines a transition zone above which the softening point temperatures are only marginally influenced by the motor oil content (Figure 4(b)). The penetration values for this binder present a transition zone for SBS contents around 5-6\%, as observed for HDPE binders.

Similar to what was observed from the previous binders, the evolution of the penetration values for the binders modified with motor oil and crumb rubber (Figure 5(a)) is mainly related with variations in the motor oil content. However, contrasting with the HDPE- and SBS-modified binders, the softening point temperatures (Figure 5(b)) are equally influenced by motor oil and crumb rubber contents (contour lines nearly at $45^{\circ}$ ). It looks like crumb rubber is not interacting with bitumen/oil as much as HDPE or SBS, acting mainly as a filler with much lower influence in the modified binder performance at higher temperatures. Moreover, the softening point temperatures are much lower than those of the previous binders, which points towards a worst rut resistance performance of the asphalt rubber binder in comparison to the HDPE- or SBSmodified binders. A transition phase apparently occurs for asphalt rubber binders combining $7.5-10 \%$ motor oil and high amounts of crumb rubber (17.5-20\%).

In order to select the best combinations of bitumen, waste motor oil and polymer for these new modified binders, a commercially available PMB 45/80-60 bitumen was used for comparison purposes (its penetration value of $50 \times 0.1 \mathrm{~mm}$ was used as target). Moreover, the new binders should meet the standard (EN 14023) limits of a PMB 45/80-60, and use the highest amounts of waste materials. Taking these conditions into account, three bitumens modified with $10 \%, 12.5 \%$ and $15 \%$ waste motor oil and 6\% HDPE (O10H6, O12.5H6 and O15H6, respectively), two bitumens modified with $7.5 \%$ and $10 \%$ waste motor oil and 5\% SBS (O7.5S5 and O10S5) and two bitumens modified with $5 \%$ and $7.5 \%$ waste motor oil and $15 \%$ or $20 \%$ crumb rubber (O5R15 and O7.5R20) were selected for rheological analysis. The selected asphalt rubber binders presented lower softening point temperatures, which are always lower than that required in EN 14023 standard $\left(60^{\circ} \mathrm{C}\right.$, according to the Portuguese conditions), selecting the ones with characteristics closer to those of the commercially available PMB used for comparison purposes.

Regarding the DSR results are presented in Table 2, it can be observed that the addition of the different waste materials increased the high temperature continuous PG of the binders, which could indicate that they will perform better than the commercial bitumens for a wider range of service temperatures. Apart from the modified binder with 5\% waste motor oil and 15\% crumb rubber, all alternative binders showed higher PGs than the commercial modified bitumen (PMB45-80). This could be seen as an advantage regarding the expected the rut resistance of the mixtures produced with these binders.

The non-recoverable creep compliance values obtained by the MSCRT are an indicator of the rut resistance under repeated loads, and they should be as small as possible to indicate an adequate performance. Thus, from the results presented in Table 3, it is possible to conclude that all the alternative modified binders showed lower values of non-recoverable creep compliance values than the conventional bitumen (B35/50) for both stress levels studied. This fact could indicate that in spite of the addition of motor oil into a PMB, its rut resistance properties would not be compromised. Moreover, in the case of the HDPE-modified binders, only the bitumen modified with $10 \%$ waste motor oil $(\mathrm{O} 10 \mathrm{H} 6)$ presented a low non-recoverable creep compliance performance better than the commercial modified bitumen. Additionally, both bitumens modified with SBS and waste motor oil presented a performance better than that of the commercial PMB. Thus, the SBS binder with the highest content of waste motor oil was selected. In relation to the 
Table 2. High-temperature performance grade of the commercial bitumens and alternative polymer-modified binders.

\begin{tabular}{lc}
\hline Binders & $\begin{array}{c}\text { High temperature } \\
\text { performance grade }\end{array}$ \\
\hline B35/50 & 64 \\
PMB45/80 & 70 \\
O10H6 & 76 \\
O12.5H6 & 82 \\
O15H6 & 76 \\
O7.5S5 & 76 \\
O10S5 & 76 \\
O5R15 & 70 \\
O7.5R20 & 76 \\
\hline
\end{tabular}

Table 3. Non-recoverable creep compliance values of commercial bitumens and alternative polymer-modified binders.

\begin{tabular}{lcc}
\hline & \multicolumn{2}{c}{ Non-recoverable creep compliance $\left(\mathrm{kPa}^{-1}\right)$} \\
\cline { 2 - 3 } Binders & Stress of $0.1 \mathrm{kPa}$ & Stress of $3.2 \mathrm{kPa}$ \\
\hline B35/50 & 2.7 & 3.0 \\
PMB45/80 & 0.8 & 1.4 \\
O10H6 & 0.9 & 1.1 \\
O12.5H6 & 0.1 & 1.6 \\
O15H6 & 0.3 & 2.2 \\
O7.5S5 & 0.1 & 0.5 \\
O10S5 & 0.1 & 0.4 \\
O5R15 & 1.2 & 2.1 \\
O7.5R20 & 0.1 & 0.3 \\
\hline
\end{tabular}

bitumens modified with crumb rubber, only the one with $7.5 \%$ waste motor oil and $20 \%$ crumb rubber presented properties better than those of the commercial PMB.

Therefore, the new modified binders that showed the most promising properties in both rheological analysis and selected to continue the study during the production of SMA mixtures were the following:

- a modified bitumen with 10\% waste motor oil and 6\% HDPE (O10H6);

- a modified bitumen with 10\% waste motor oil and 5\% SBS (O10S5) and

- a modified bitumen with $7.5 \%$ waste motor oil and 20\% crumb rubber (O7.5R20).

The penetration and softening point values of these binders, as well as the production and compaction temperatures obtained when dynamic viscosity results are nearly 0.3 (mixing equiviscosity) and $3 \mathrm{~Pa} . \mathrm{s}$ (compaction equiviscosity), are presented in Table 4 . The same properties are also presented for the conventional binder (B35/50) and the commercially available PMB (PMB 45/80), both of them used for comparison purposes. Asphalt mixtures with these commercial bitumens, namely SMA-BF0.3 (with a B35/50 bitumen and $0.3 \%$ fibres) and SMAPMB45/80 (with a PMB45/80 binder) were also evaluated and compared with the asphalt mixtures incorporating the new modified binders. 
Table 4. Binder properties and corresponding mixing/compaction temperatures.

\begin{tabular}{lcccc}
\hline & $\begin{array}{c}\text { Penetration at } 25^{\circ} \mathrm{C} \\
(0.1 \mathrm{~mm})\end{array}$ & $\begin{array}{c}\text { Softening point } \\
\left({ }^{\circ} \mathrm{C}\right)\end{array}$ & Mixing & Compaction \\
\cline { 4 - 5 } Binders & 35 & 54 & 160 & 120 \\
B35/50 & 50 & 60 & 180 & 130 \\
PMB 45/80 & 51 & 83 & 180 & 130 \\
O10H6 & 50 & 80 & 180 & 130 \\
O10S5 & 49 & 59 & 180 & 140 \\
O7.5R20 & & & & \\
\hline
\end{tabular}

\subsection{Binder drainage of SMA mixtures}

Five SMA mixtures were prepared with the three new modified binders and with the two binders used as reference. Since SMA mixtures have significantly high binder contents, their binder drainage should be evaluated. According to Figure 6, it should be noted that the four SMA mixtures using modified bitumens present higher binder drainage values than the one with conventional bitumen and fibres. Nevertheless, the binder drainage values of all SMA mixtures are lower than those recommended $(<0.2 \%)$ in the literature (Blazejowski, 2011).

It is confirmed that drainage inhibitors (acrylic fibres) are not needed in SMA mixtures with PMBs to avoid the separation between the binder/mastic and the aggregates in the mixture. Comparing the results of the different mixtures produced with PMBs, it should be noted that the new modified binders do not have higher binder drainage values than the commercially available PMB. Among these, the SBS-modified binder was the one with the best performance.

\subsection{Mechanical characterisation of SMA mixtures}

The tensile strength ratio (TSR) value, which is the ratio between the IDT strength of unconditioned and water conditioned specimens, was used to measure the water sensitivity of the different SMA mixtures. A minimum TSR value of 0.70 is recommended (Lottman, 1982), but more conservative agencies specify a minimum TSR value of 0.80 (Asphalt Institute, 2001; Brown et al., 2009; Roberts, Kandhal, Brown, Lee, \& Kennedy, 1996). The TSR results obtained for the reference SMA mixtures, namely the mixture with conventional bitumen and fibres (SMA-BF0.3) and the mixture with commercially available PMB (SMA-PMB45/80) were, respectively, 0.87 and 0.80 . The SMA mixtures produced with the new modified binders, namely SMA-O10H6, SMA-O10S5 and SMA-O7.5R20, presented higher TSR values than those of the reference SMA

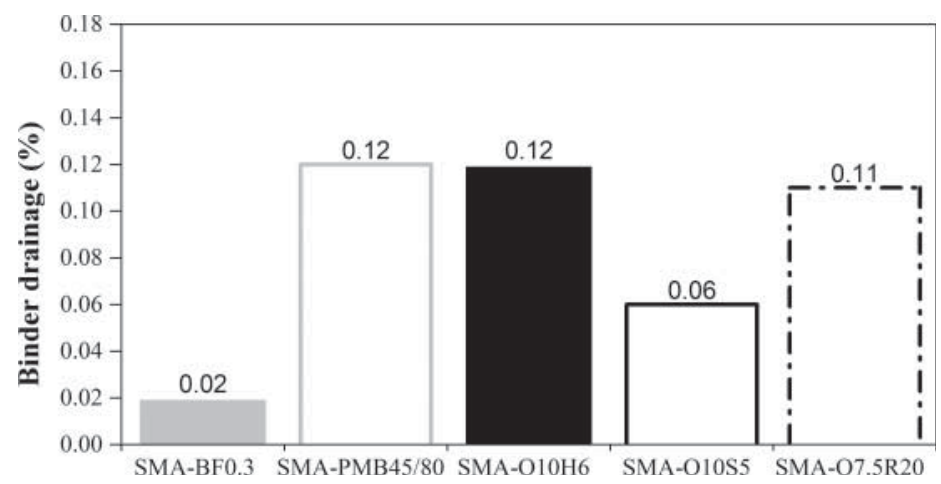

Figure 6. Binder drainage values of the studied mixtures. 
mixtures, namely $0.89,0.96$ and 0.88 . All these TSR values are above the minimum limits recommended for this property, even when considering more conservative values.

The stiffness modulus of the SMA mixtures was obtained by carrying out a four-point bending repetitive loading test on prismatic beam specimens, at $0^{\circ} \mathrm{C}, 10^{\circ} \mathrm{C}, 20^{\circ} \mathrm{C}$ and $30^{\circ} \mathrm{C}$ temperatures. The master curves of the stiffness modulus and phase angle of the different SMA mixtures, for a reference temperature of $20^{\circ} \mathrm{C}$, were obtained by using the IRIS analysis software, and they are presented in Figure 7.

Analysing these results, it is possible to observe that the stiffness and phase angle values of the mixtures with commercial PMB and with HDPE or SBS are more influenced by the test temperature, possibly due to the higher interaction between those polymers and the bitumen/oil, in comparison with the use of fibres or crumb rubber. In fact, the latter have higher stiffness and/or lower phase angle values at very low frequencies (equivalent to high temperatures), due to the stabilising effect of these additives, and lower stiffness and higher phase angles at higher frequencies. Thus, for pavement design in cold to mild climates (corresponding to higher frequencies in Figure 7), the solutions with commercial PMB, HDPE or SBS may be the best solutions, because they present higher stiffness moduli, resulting in a reduction on the necessary pavement thickness and overall cost (assuming an equivalent fatigue performance). Furthermore, between these three mixtures, the one with HDPE presents a higher stiffness modulus and lower phase angle for a wide range of frequencies, definitely because plastomers (i.e. HDPE) are stiffer than elastomers (i.e. commercial PMB and SBS), even though they can present a lower fatigue resistance, namely for low service temperatures.

The durability of SMA mixtures should also be associated with a good fatigue cracking resistance, whose results are presented in Figure 8. It is evident that the mixture with motor oil and SBS (SMA-O10S5) presents the best fatigue cracking resistance between the developed mixtures, being equivalent or slightly better than the reference mixture with the commercially available PMB (SMA-PMB45/80). This excellent performance results from the elastic properties of SBS polymer, which may have been improved by its combination with the motor oil used as asphalt extender. The fatigue cracking resistance of the remaining mixtures was acceptable, even though it was clearly lower than that of the SBS and commercial PMB mixtures. The mixture with motor oil and HDPE (SMA-O10H6) shows a fatigue cracking performance similar to the conventional mixture with bitumen and fibres (SMA-BF0.3), but it should be emphasised
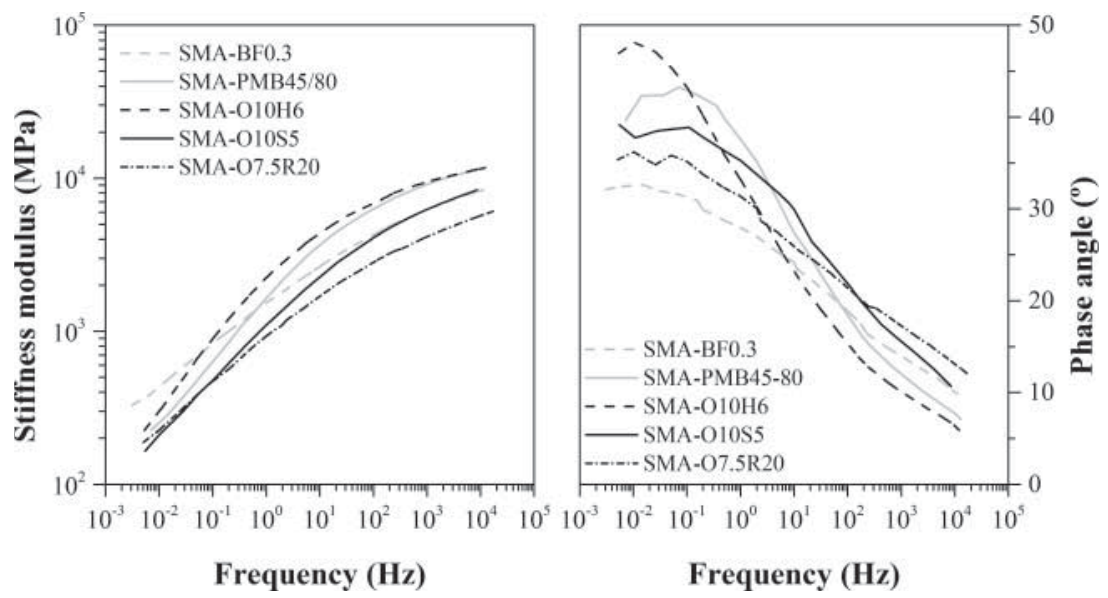

Figure 7. Stiffness modulus and phase angle master curves $\left(T_{\text {ref }}=20^{\circ} \mathrm{C}\right)$ of the studied mixtures. 


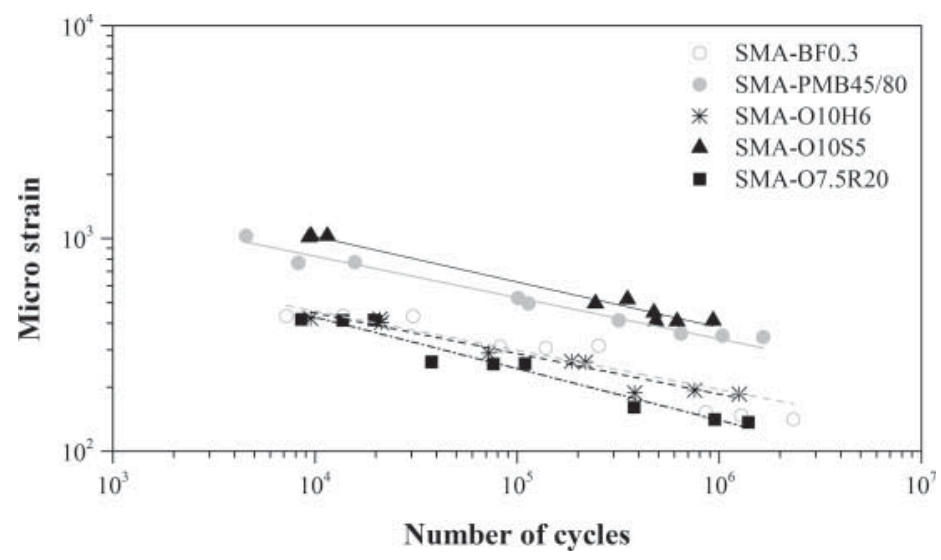

Figure 8. Four-point bending fatigue test results of the studied mixtures.

Table 5. Fatigue cracking parameters of the studied mixtures.

\begin{tabular}{|c|c|c|c|c|c|}
\hline \multirow[b]{2}{*}{ Mixtures } & \multicolumn{2}{|c|}{ Fatigue parameters $\left(\varepsilon=a \times N^{-b}\right)$} & \multirow[b]{2}{*}{$R^{2}$} & \multirow{2}{*}{$\begin{array}{c}\mathrm{N} 100 \\
\left(10^{6} \text { cycles }\right)\end{array}$} & \multirow[b]{2}{*}{$\varepsilon^{6}\left(10^{-6}\right)$} \\
\hline & $a$ & $b$ & & & \\
\hline SMA-BF0.3 & 3779 & 0.223 & 0.90 & 12 & 175 \\
\hline SMA-PMB45/80 & 4439 & 0.185 & 0.98 & 840 & 346 \\
\hline SMA-O10H6 & 2670 & 0.194 & 0.95 & 23 & 183 \\
\hline SMA-O10S5 & 7312 & 0.214 & 0.98 & 530 & 382 \\
\hline SMA-O7.5R20 & 3904 & 0.241 & 0.96 & 4 & 140 \\
\hline
\end{tabular}

that this result was obtained with a waste plastomer. The mixture with motor oil and crumb rubber shows the worst fatigue cracking resistance, which may be a consequence of the small effect on the fracture resistance produced by a reduced interaction between the bitumen/oil and the vulcanised polymers of the crumb rubber.

Taking the fatigue cracking results presented in Figure 8 into consideration, it is also possible to compute the number of cycles to failure (the fatigue cracking resistance) resulting from a fatigue test performed at 100 tensile microstrain $\left(\mathrm{N}_{100}\right)$ and the tensile microstrain that causes a fatigue cracking resistance of $1 \times 10^{6}$ cycles $\left(\varepsilon_{6}\right)$. These fatigue cracking parameters are presented in Table 5.

The accuracy of these calculations, using the fatigue life equations of all mixtures, is assured by very high values of the coefficient of determination (higher than 0.9 ). The mixtures with oil and SBS (SMA-O10S5) or with commercial PMB (SMA-PMB45/80) confirmed their excellent performance, presenting a fatigue cracking resistance 50-80 times higher than the mixture with conventional bitumen and fibres (SMA-BF0.3) and doubling the tensile strain they are able to sustain on each loading cycle. The fatigue performance of the mixture with HDPE (SMA$\mathrm{O} 10 \mathrm{H} 6)$ may also be seen as relevant, doubling the fatigue cracking resistance of the reference mixture SMA-BF0.3. The mixture with crumb rubber (SMA-O7.5R20) does not seem to be a good solution, in comparison with the remaining mixtures, because its fatigue life is only one quarter of that obtained for the reference mixture SMA-BF0.3.

The permanent deformation results obtained in the wheel tracking test (Figure 9) were used to evaluate the mechanical performance of the SMA mixtures at high service temperatures $\left(60^{\circ} \mathrm{C}\right)$. 


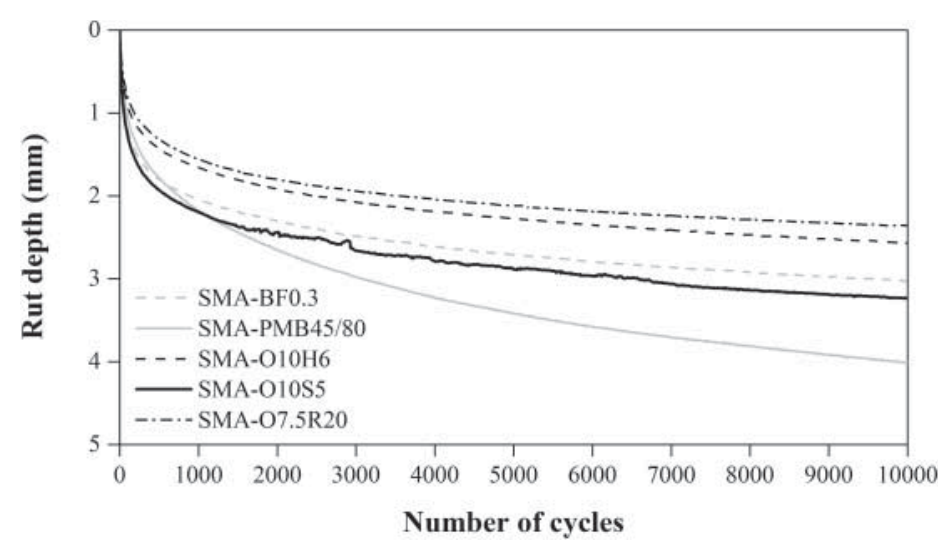

Figure 9. Wheel tracking test results of the studied mixtures.

Table 6. Rut resistance parameters of the studied mixtures.

\begin{tabular}{lccc}
\hline Mixtures & $\begin{array}{c}\text { WTS }_{\text {AIR }} \\
\left(\mathrm{mm} / 10^{3} \text { cycles }\right)\end{array}$ & $\begin{array}{c}\mathrm{PRD}_{\text {AIR }} \\
(\%)\end{array}$ & $\begin{array}{c}\mathrm{RD}_{\text {AIR }} \\
(\mathrm{mm})\end{array}$ \\
\hline SMA-BF0.3 & 0.06 & 7.38 & 3.03 \\
SMA-PMB45/80 & 0.12 & 9.97 & 4.01 \\
SMA-O10H6 & 0.06 & 6.27 & 2.57 \\
SMA-O10S5 & 0.07 & 7.97 & 3.24 \\
SMA-O7.5R20 & 0.05 & 5.76 & 2.36 \\
\hline
\end{tabular}

In general, all mixtures presented a good rut resistance, with low deformation rates during the test, even though the studied mixtures have a high binder content $(5.8 \%)$.

The very good performance of the mixtures with the new modified binders developed in this study (with waste motor oil, and HDPE, SBS or crumb rubber) should be highlighted. In fact, these mixtures presented an improved rut resistance when compared with the mixture with commercially available PMB (SMA-PMB45/80), even when they are using a significant amount of waste motor oil. The rut resistance of the reference mixture with conventional bitumen and fibres (SMA-BF0.3) was similar to that of the mixtures with waste motor oil and HDPE, SBS or crumb rubber, mainly due to the stabilising effect of the fibres.

The permanent deformation test results can be used to calculate some parameters specified in EN 12697-22 standard, namely the wheel tracking slope (WTS $\mathrm{WIR}_{\mathrm{A}}$ ), proportional maximum rut depth $\left(\mathrm{PRD}_{\mathrm{AIR}}\right)$ and maximum rut depth $\left(\mathrm{RD}_{\mathrm{AIR}}\right)$. These values are presented in Table 6.

From the analysis of those parameters, it was confirmed that all SMA mixtures presented a good performance. In fact, the mixture produced with the commercial PMB (SMA-PMB45/80) showed the worst permanent deformation performance, but the values of WTS $\mathrm{AIR}\left(0.12 \mathrm{~mm} / 10^{3}\right.$ cycles) and $\mathrm{PRD}_{\mathrm{AIR}}(9.97 \%)$ are still very good for common road-paving works. It should be noted that the best rut performance was the one from the mixture with motor oil and crumb rubber, which presented the lowest $\operatorname{WTS}_{\mathrm{AIR}}\left(0.05 \mathrm{~mm} / 10^{3}\right.$ cycles $)$ and $\mathrm{PRD}_{\mathrm{AIR}}(5.76 \%)$ values. When compared to the other mixtures, this improved behaviour could be mainly related to the higher polymer content used in the asphalt rubber, but also with the lower content of motor oil. Nevertheless, the rut resistance of the three mixtures with the new modified binders and the reference mixture with conventional bitumen and fibres was almost equivalent (WTS $\mathrm{SIR}_{\text {values }}$ range only between 0.05 and $0.07 \mathrm{~mm} / 10^{3}$ cycles). 


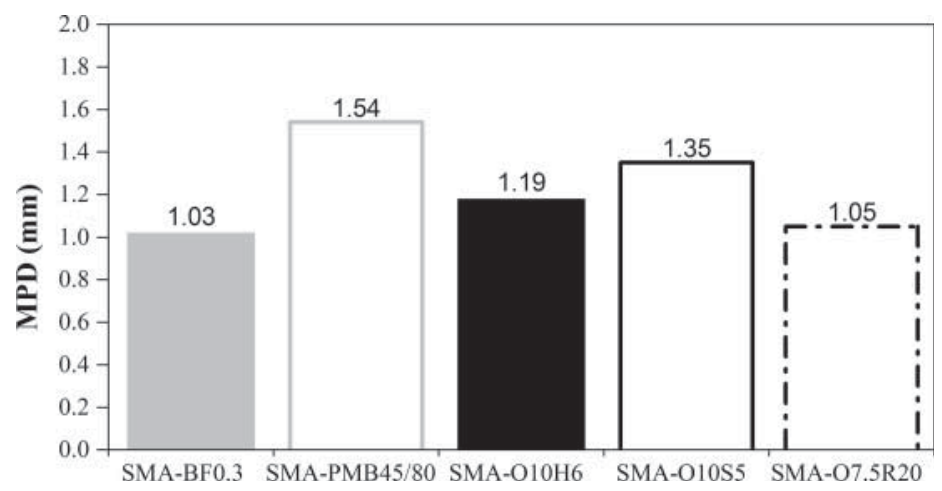

Figure 10. Mean profile depth (MPD) test results of the studied mixtures.

\subsection{Surface characterisation of SMA mixtures}

The surface characteristics of SMA mixtures are typically defined by their high macrotexture, and several authors mentioned that their MPD should be greater than $1.0 \mathrm{~mm}$ (Kogbara, Masad, Kassem, Scarpas, \& Anupam, 2016; Vaiana, Capiluppi, Gallelli, Iuele, \& Minani, 2012). In fact, these mixtures use a high amount of coarse aggregates $(74 \%)$ contributing to an increase in the surface roughness. However, taking into account that the new modified binders used in this study could affect the typical MPD values, that possibility was assessed in this part of the work (Figure 10). It was concluded that all SMA mixtures presented MPD values higher than $1.0 \mathrm{~mm}$, as required for this type of mixture in order to have a safe and comfortable surface for road users. Furthermore, it should be highlighted that the SMA mixtures with the new binders incorporating waste materials showed higher MPD values when compared to those of the reference mixture with conventional bitumen and fibres (SMA-BF0.3).

The use of significant amounts of waste motor oil in some binders developed for SMA production could also negatively affect their slip/skid resistance, thus justifying the evaluation of that surface characteristic in this study. Consequently, British pendulum tests were carried out in SMA slabs produced in the laboratory, without wearing, in order to emphasise the effect of the bitumen film of each mixture/slab on the corresponding surface characteristics. From the analysis of the pendulum test values (PTV) (Figure 11), it can be concluded that, on the one hand, the SMA mixtures with motor oil and HDPE or SBS polymers presented a lower slip/skid resistance (60-64 PTV units) in comparison to the reference mixture with bitumen and fibres (66 PTV units). On the other hand, the mixture with motor oil and crumb rubber maintained/improved the slip/skid resistance (67 PTV units) in comparison to the same reference mixture, mainly due to the positive effect or crumb rubber particles and the lower amount of motor oil used in this case. Nonetheless, according to the Portuguese specification (EP, 2014), the minimum value for slip/skid resistance of a surface course is $60 \mathrm{PTV}$, and all these SMA mixtures are able to meet that specification requirement, assuring the necessary safety for road users.

\subsection{Environmental characterisation of SMA mixtures}

The use of waste materials in asphalt mixtures could bring additional risks to the environment and human health, as previously mentioned. Thus, it is fundamental to identify and quantify the heavy metals' presence associated to the leachates of the studied mixtures, and compare them to the specified limits (EN 13473-1). Through the chemical analysis of the SMA mixtures' eluates 


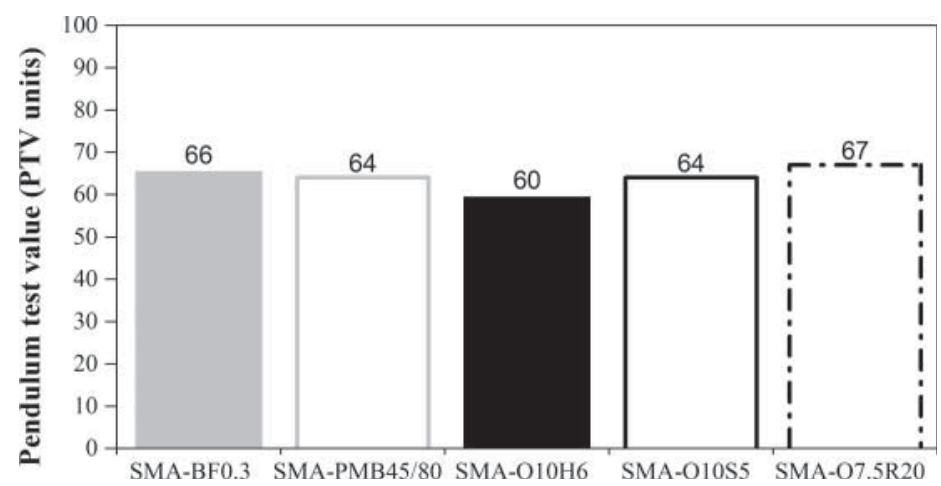

Figure 11. Pendulum test values of the studied mixtures.

Table 7. Amount of heavy metals observed in the eluates of the studied mixtures.

\begin{tabular}{lcccccc}
\hline & & \multicolumn{5}{c}{ Mixtures } \\
\cline { 3 - 7 } $\begin{array}{l}\text { Parameters } \\
(\mathrm{mg} / \mathrm{kg})\end{array}$ & Limits & SMA-BF0.3 & SMA-PMB45/80 & SMA-O10H6 & SMA-O10S5 & SMA-O7.5R20 \\
\hline Cadmium & 0.04 & $<0.04$ & $<0.04$ & $<0.04$ & $<0.04$ & $<0.04$ \\
Chromium & 0.50 & $<0.50$ & $<0.50$ & $<0.50$ & $<0.50$ & $<0.50$ \\
Copper & 2.00 & $<0.25$ & 0.42 & $<0.25$ & $<0.25$ & $<0.25$ \\
Nickel & 0.40 & $<0.30$ & $<0.30$ & $<0.30$ & $<0.30$ & $<0.30$ \\
Lead & 0.50 & $<0.30$ & $<0.30$ & $<0.30$ & $<0.30$ & $<0.30$ \\
Zinc & 4.00 & 0.43 & 0.12 & 0.14 & 0.49 & 0.24 \\
\hline
\end{tabular}

(Table 7), it is possible to verify that all mixtures comply with the maximum imposed limits for all heavy metals evaluated in this study.

It should be emphasised that the less-than signs $(<)$ were used in Table 7 whenever the test equipment was not able to quantify with more accuracy the heavy metals' presence, although it can be assured that the measured value is lower than a certain limit (typically the limits mentioned in the specifications). Comparing the heavy metals' presence in the eluates of the studied mixtures, it can be observed that the presence of zinc is lower in the mixture with commercial $\mathrm{PMB}$, but the presence of copper is higher. The highest concentration of zinc was obtained for the mixture with SBS (SMA-O10S5), while the mixtures with HDPE or crumb rubber have higher amounts of waste material but showed lower concentration of heavy metals (i.e. zinc). In fact, the concentration of zinc is higher in the reference mixture without waste materials (SMA-BF0.3). Thus, it can be assumed that the asphalt mixtures with waste materials developed in this work do not present risks both for the environment and for the human health.

\section{Conclusions}

The main objective of this work was to develop asphalt mixtures with sustainable binders incorporating waste materials (motor oil and different polymers). SMA mixtures were produced with these new binders, and their mechanical, surface and environmental characteristics were evaluated in comparison to reference mixtures produced with a conventional bitumen and a commercially available PMB.

In general, it was concluded that these eco-friendly binders/mixtures with waste materials are excellent solutions for road-paving works because they have a good mechanical and surface 
performance without compromising the environment or the human health. The best solutions used nearly $10 \%$ waste motor oil as an asphalt extender, combined with 5-6\% of waste HDPE or SBS polymers. Another solution with $20 \%$ crumb rubber was also developed, even though with inferior performance. Furthermore, during this work it was possible to draw the following conclusions:

- The content of waste motor oil mainly influences the penetration values of the new modified binders, while the amount of polymer has a higher effect on the softening point temperatures.

- The rheological tests were important to adequately characterise the bitumens modified with the wastes studied in this work; and should be used to select the best ones for asphalt mixtures production;

- The high-temperature PG of all alternative binders developed in this work was higher than that of a commercially available PMB, but only some combinations of waste motor oil and polymers presented a better performance in the MSCRT;

- All the new modified binders with waste materials improved the water sensitivity resistance and the rut resistance of the corresponding SMA mixtures. Furthermore, the combination of waste motor oil with SBS and HDPE polymers also increased the fatigue cracking resistance and the stiffness moduli, thus being excellent solutions when designing pavements in cold to mild climates. The fatigue performance of the SMA mixture with motor oil and crumb rubber was not so good, but its use may be valuable in hot climates.

- The use of waste motor oil as an asphalt extender in the new modified binders slightly reduced the PTV values, but all the SMA mixtures meet the slip/skid resistance specification requirement. Moreover, the macrotexture (MPD values) of the SMA mixtures was improved, when using the new binders incorporating waste materials.

- The SMA eluates analysed in this study showed that all mixtures comply with the maximum imposed limits required for all heavy metals evaluated. This is a good sign that the reuse of waste materials in asphalt mixtures may not result in harmful leachates with potential risks for both the environment and the human health.

\section{Disclosure statement}

No potential conflict of interest was reported by the authors.

\section{Funding}

The authors gratefully acknowledge the funding by the Portuguese Government and EU/FSE within a PhD fellowship (SFRH/BD98379/2013) of the FCT, in the scope of POPH/QREN, by ERDF (European Regional Development Fund) funds through the Competitiveness Factors Operational Programme (COMPETE).

\section{ORCID}

Sara Fernandes (D) http://orcid.org/0000-0002-7247-0779

Hugo M. R. D. Silva (D) http://orcid.org/0000-0003-4589-5250

Joel R. M. Oliveira (iD http://orcid.org/0000-0002-8077-9792

\section{References}

Ahmedzade, P. (2013). The investigation and comparison effects of SBS and SBS with new reactive terpolymer on the rheological properties of bitumen. Construction and Building Materials, 38, 285-291. doi:10.1016/j.conbuildmat.2012.07.090 
Arslan, D., Gürü, M., Çubuk, M. K., \& Çubuk, M. (2011). Improvement of bitumen and bituminous mixtures performances by triethylene glycol based synthetic polyboron. Construction and Building Materials, 25(10), 3863-3868. doi:10.1016/j.conbuildmat.2011.04.007

Asphalt Institute. (2001). Superpave ${ }^{\circledR}$ mix design (3rd ed.). Lexington, KY: Asphalt Institute.

Attaelmanan, M., Feng, C. P., \& Ai, A.-H. (2011). Laboratory evaluation of HMA with high density polyethylene as a modifier. Construction and Building Materials, 25(5), 2764-2770. doi:10.1016/j.conbuildmat.2010.12.037

Blazejowski, K. (2011). Stone matrix asphalt-theory and practice (Vol. 201). Boca Raton, FL: CRC Press.

Branco, F., Pereira, P., \& Picado, L. (2006). Pavimentos rodoviários. Coimbra: Edições Almedina.

Brown, E. R., Kandhal, P. S., Roberts, F. L., Kim, Y. R., Lee, D.-Y., \& Kennedy, T. W. (2009). Hot mix asphalt materials, mixture design, and construction. Lanham, MD: National Asphalt Pavement Association Research and Education Foundation.

Dehouche, N., Kaci, M., \& Mokhtar, K. A. (2012). Influence of thermo-oxidative aging on chemical composition and physical properties of polymer modified bitumens. Construction and Building Materials, 26(1), 350-356. doi:10.1016/j.conbuildmat.2011.06.033

EP. (2014). Caderno de Encargos Tipo Obra, Capítulo 15.03 - Pavimentação - Métodos Construtivos. Almada: Estradas de Portugal S.A.

Fernandes, S., Costa, L., Silva, H., \& Oliveira, J. (2015). Effect of incorporating different waste materials in bitumen. Materiais 2015: VII International Materials Symposium, Porto, Portugal.

Fuentes-Audén, C., Sandoval, J. A., Jerez, A., Navarro, F. J., Martínez-Boza, F. J., Partal, P., \& Gallegos, C. (2008). Evaluation of thermal and mechanical properties of recycled polyethylene modified bitumen. Polymer Testing, 27(8), 1005-1012. doi:10.1016/j.polymertesting.2008.09.006

Gardete, D., Santos, L. P., \& Capitão, S. (2011). Formulação volumétrica e desempenho de misturas betuminosas stone mastic asphalt. XVI CILA - Congresso Ibero-Latinoamericano do Asfalto, Rio de Janeiro, Brasil.

González, V., Martínez-Boza, F. J., Gallegos, C., Pérez-Lepe, A., \& Páez, A. (2012). A study into the processing of bitumen modified with tire crumb rubber and polymeric additives. Fuel Processing Technology, 95(0), 137-143. doi:10.1016/j.fuproc.2011.11.018

Jia, X., Huang, B., Bowers, B. F., \& Zhao, S. (2014). Infrared spectra and rheological properties of asphalt cement containing waste engine oil residues. Construction and Building Materials, 50(0), 683-691. doi:10.1016/j.conbuildmat.2013.10.012

Júnior, A. F. A., Battistelle, R. A., Bezerra, B. S., \& Castro, R. (2012). Use of scrap tire rubber in place of SBS in modified asphalt as an environmentally correct alternative for Brazil. Journal of Cleaner Production, 33, 236-238. doi:10.1016/j.jclepro.2012.03.039

Kalantar, Z. N., Karim, M. R., \& Mahrez, A. (2012). A review of using waste and virgin polymer in pavement. Construction and Building Materials, 33, 55-62. doi:10.1016/j.conbuildmat.2012.01.009

Kogbara, R. B., Masad, E. A., Kassem, E., Scarpas, A., \& Anupam, K. (2016). A state-of-the-art review of parameters influencing measurement and modeling of skid resistance of asphalt pavements. Construction and Building Materials, 114, 602-617. doi:10.1016/j.conbuildmat.2016.04.002

Kök, B. V., \& Çolak, H. (2011). Laboratory comparison of the crumb-rubber and SBS modified bitumen and hot mix asphalt. Construction and Building Materials, 25(8), 3204-3212. doi:10.1016/j.conbuildmat.2011.03.005

Lo Presti, D. (2013). Recycled tyre rubber modified bitumens for road asphalt mixtures: A literature review. Construction and Building Materials, 49, 863-881. doi:10.1016/j.conbuildmat.2013.09.007

Lottman, R. P. (1982). Predicting moisture-induced damage to asphaltic concrete field evaluation. Retrieved from NCHRP 246.

Nejad, M., Azarhoosh, F., \& Hamedi, A., \& H, G. (2014). Effect of high density polyethylene on the fatigue and rutting performance of hot mix asphalt - a laboratory study. Road Materials and Pavement Design, 15(3), 746-756. doi:10.1080/14680629.2013.876443

Peralta, J., Silva, H. M. R. D., Hilliou, L., Machado, A. V., Pais, J., \& Williams, C. R. (2012). Mutual changes in bitumen and rubber related to the production of asphalt rubber binders. Construction and Building Materials, 36, 557-565. doi:10.1016/j.conbuildmat.2012.06.030

Peralta, J., Silva, H. M. R. D., Williams, R. C., Rover, M., \& Machado, A. V. A. (2013). Development of an innovative bio-binder using asphalt-rubber technology. International Journal of Pavement Research and Technology, 6(4), 447-456.

Peralta, J., Williams, R. C., Silva, H. M. R. D., \& Machado, A. V. (2013). Combining asphalt-rubber (AR) and fast-pyrolysis bio-il to create a binder for flexible pavements. Braga: WASTES: Solutions, Treatments and Opportunities. 
Reinke, G., Hanz, A., Anderson, R. M., Ryan, M., Engber, S., \& D. Herlitzka. (2016). Impact of re-refined engine oil bottoms on binder properties and mix performance on two pavements in Minnesota. $\mathrm{E} \& \mathrm{E}$ Congress 2016, Prague, Czech Republic.

Roberts, F. L., Kandhal, P. S., Brown, E. R., Lee, D.-Y., \& Kennedy, T. W. (1996). Hot mix asphalt materials, mixture design and construction. Lanham, MD: Transportation Research Board.

Sarang, G., Lekha, B. M., Krishna, G., \& Ravi Shankar, A. U. (2016). Comparison of stone matrix asphalt mixtures with polymer-modified bitumen and shredded waste plastics. Road Materials and Pavement Design, 933-945. doi:10.1080/14680629.2015.1124799

Vaiana, R., Capiluppi, G. F., Gallelli, V., Iuele, T., \& Minani, V. (2012). Pavement surface performances evolution: An experimental application. Procedia - Social and Behavioral Sciences, 53, 1149-1160. doi:10.1016/j.sbspro.2012.09.964

Yildirim, Y. (2007). Polymer modified asphalt binders. Construction and Building Materials, 21(1), 66-72. doi:10.1016/j.conbuildmat.2005.07.007

Yousefi Kebria, D., Moafimadani, S. R., \& \& Goli, Y. (2015). Laboratory investigation of the effect of crumb rubber on the characteristics and rheological behaviour of asphalt binder. Road Materials and Pavement Design, 16(4), 946-956. doi:10.1080/14680629.2015.1042015 